\section{Approach-avoidance behavior of rats with septal lesions under massed and distributed trials*}

\author{
PETER A. FRIED \\ Carleton University, Ottawa, Ont., Canada
}

Rats with bilateral septal lesions were tested in a straight alley approach-avoidance task under either massed or spaced intertrial conditions. Under both intervals, the experimental animals showed significantly less avoidance behavior than controls when a previously rewarded response was punished. However, all $S s$ in all conditions demonstrated their maximum approach-avoidance conflict in the same location in the alley. The results were discussed in relation to previous reports of rats with partial and complete hippocampal lesions.

Lesions of the hippocampus and septum in rats have been shown to result in dysfunctions which appear to be, in many respects, quite similar and have generally been described as a loss of some sort of response-suppressing mechanism (McCleary, 1966; Thomas, Hostetter, \& Barker, 1968). However, the data obtained from a number of recent reports suggest that, in spite of the overt similarity of the consequences of injury to the hippocampus or septum, definite differences exist in terms of task parameters which elicit the loss of inhibition. For example, the effect of septal lesions in an approach-avoidance problem is influenced considerably by postoperative approach training (Fried, 1971; Middaugh \& Lubar, 1970 ), whereas the effect of hippocampal lesions is determined, to a large extent, by a preoperatively established set (Fried \& Goddard, 1967; Wishart \& Mogenson, 1970).

In passive avoidance tasks, the performance of rats with hippocampal lesions has been related to the intertrial interval (ITI). Liss (1968) reported that, under massed conditions of approximately $35 \mathrm{sec}$ ITI, no deficits in passive avoidance behavior were observed in hippocampal-lesioned rats, whereas under a spaced ITI of one trial per day a loss of response inhibition was displayed by the operated group. The present studies were designed to investigate whether a massed or spaced ITI would also affect septal-lesioned rats in the differential manner. The task used was one in which animals were observed during the development of an approach-avoidance conflict and during the resolution of the conflict in favor of approach behavior.

*This research was supported by Grant DRB 9425-24 from the Defence Research Board. I thank B. Deslauriers for technical assistance and C. Stark for histological assistance. performed under Equi-Thesin an esthesia $(3.2 \mathrm{cc} / \mathrm{kg})$. Electrolytic lesions were produced in experimental animals by passing $3-\mathrm{mA}$ anodal current for $10 \mathrm{sec}$ through a stainless steel needle, insulated except for $1 / 2 \mathrm{~mm}$ at the tip. The electrode was aimed at the lateral edge of the medial septal nucleus using coordinates described elsewhere (Fried, 1971). Rats in the control group were anesthetized, placed in the stereotaxic instrument and had their scalps incised. The lesions were verified histologically with the procedures reported elsewhere (Fried, 1971).

The apparatus was a $2.5-\mathrm{m}$ black alley containing a $17-\mathrm{cm}$ startbox and $27-\mathrm{cm}$ goalbox with a foodcup. With the raising of the guillotine start door, a timer was activated. This timer stopped and a second started when a photocell beam, $23 \mathrm{~cm}$ in front of the start door, was broken. The breaking of a photocell beam over the foodcup stopped the secod timer and, on appropriate trials, delivered ,40-mA 60 -cycle ac for $.1 \mathrm{sec}$ to the floor of the goalbox.

Alley training began 8 days postoperatively with the animals being placed on a 23.h food-deprivation

DISTRIBUTED TRIALS

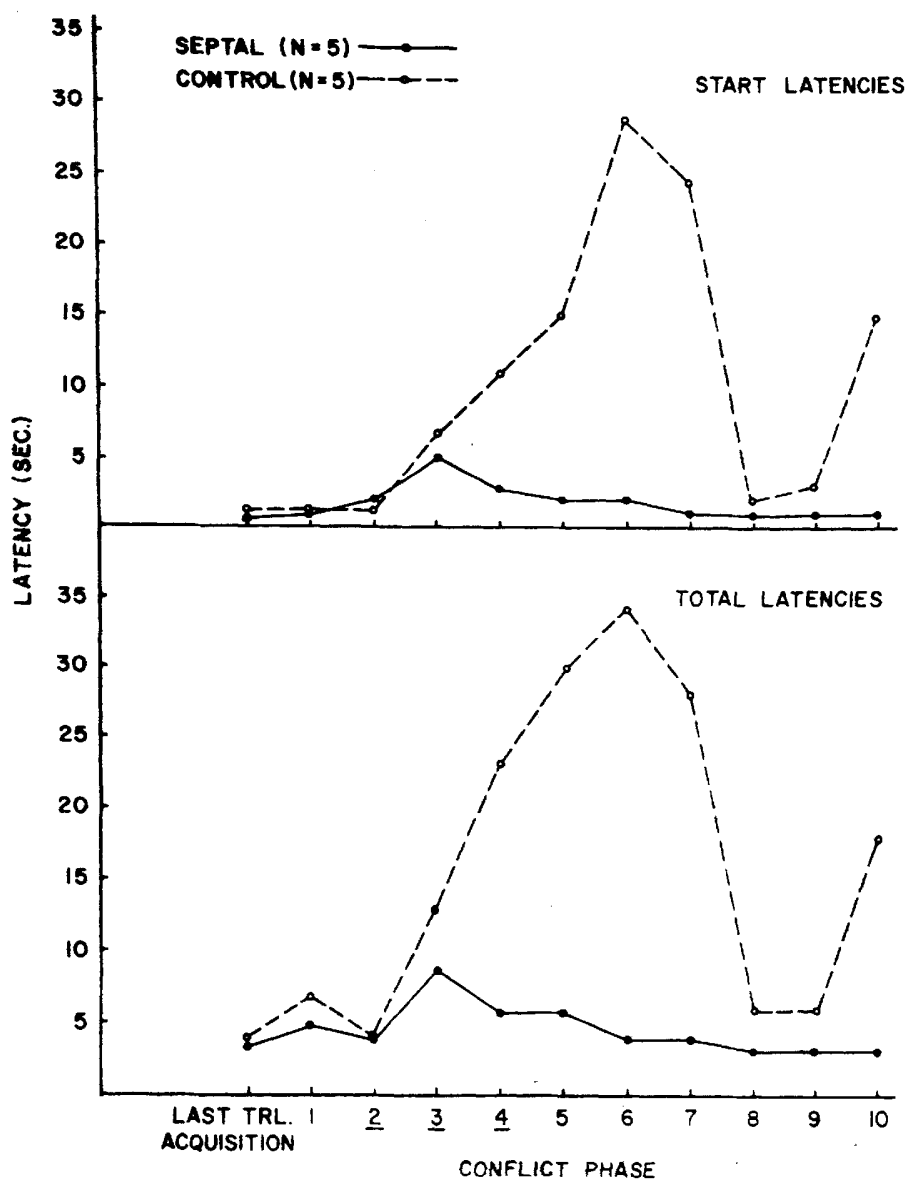

Fig. 1. Mean start (top) and total (bottom) latencies of the last trial of acquisition and the 10 trials of the conflict phase under massed conditions. 


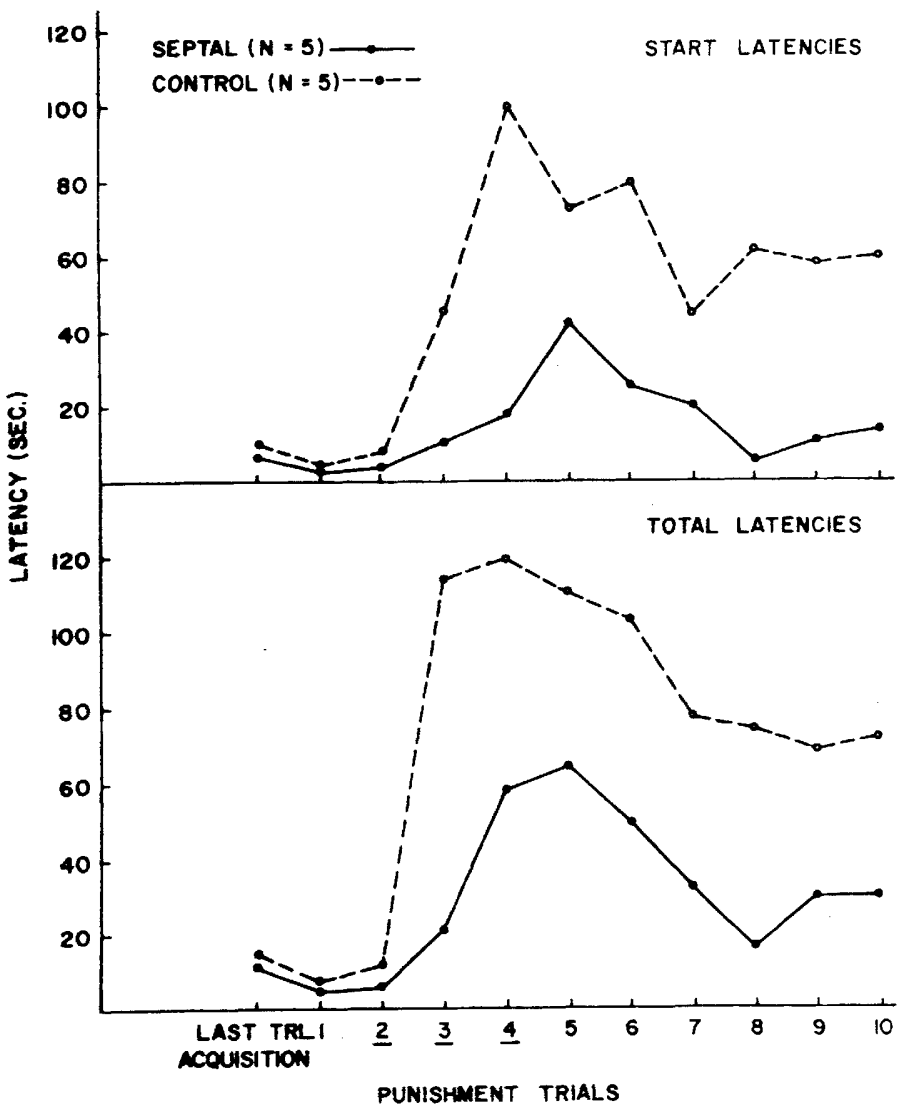

Fig. 2. Mean start (top) and total (bottom) latencies of the last trial of acquisition and the 10 trials of theconflict phase under spaced conditions.

regimen. Following 3 days of apparatus familiarization (Fried, 1971), animals received 20 trials of acquisition training. Two $45-\mathrm{mg}$ food pellets were used as positive reinforcement on each trial during the acquisition phase and during the subsequent conflict phase. Each trial consisted of placing the animal in the startbox, raising the guillotine door and allowing the rat to run to the foodcup in the goalbox. Start time (first timer) and total time (first plus second timer) are the dependent measures reported in this paper. Following the 20 acquisition trials, a 10-trial conflict phase of the study began. It consisted of one trial similar to those in the acquisition phase followed by three trials in which, when the animal took the food, footshock was administered. The remaining six trials consisted of positive reinforcement without footshock. If, at any point in the experiment, an animal required more than $120 \mathrm{sec}$ to stop the last timer, it was placed in the goalbox for $20 \mathrm{sec}$ and, if scheduled, given a footshock. A latency of $120 \mathrm{sec}$ was recorded on those trials.
Five experimental and five control animals were tested with an ITI of approximately $30 \mathrm{sec}$. Under these massed conditions, 20 acquisition trials were given on one day and the final 10 trials were given $24 \mathrm{~h}$ later. The remaining five experimental and five control animals were tested using a spaced ITI of one trial every $24 \mathrm{~h}$.

\section{RESULTS}

Microscopic examination of the lesions revealed damage similar to that reported elsewhere (Fried, 1971). Animals in the experimental groups had extensive damage of the medial and lateral septal nuclei and most $\mathrm{Ss}$ also sustained injury to the diagonal band and superior fornix.

\section{Massed Trials}

During the 20 acquisition trials, the septal-lesioned Ss acquired a rapid response sooner than did the experimental $\mathrm{Ss}(\mathrm{p}<.05)$, although by the last trial of this phase both groups were quite similar. The start and total latencies of the last trial of acquisition and the 10 trials of the conflict phase are presented in Fig. 1. As can be seen graphically, on the trials in which long latencies occurred in both the experimental and control groups, a large amount of that latency was due to the length of time spent in the startbox area. Analysis of variance and subsequent Newman-Keuls tests indicated that from the third trial of the conflict phase until the end of testing, the septal damaged animals ran significantly faster than thycontrol Ss ( $\mathrm{p}<.05$ in all cases ).

Distributed Trials

During the acquisition phase, the septal animals ran significantly faster than the control animals $(p<.05)$, but by the end of 20 trials, the two groups were indistinguishable. The start and total latencies of the last trial of acquisition and the 10 trials of the conflict phase are presented in Fig. 2. The ordinates of this figure differ from those of Fig. 1. Although the overall latencies of both groups are considerably less than the latencies found under massed conditions, the same relationships between the experimental and control groups were found. The start latencies contribute a large proportion of the total time for the experimental and control groups. Analysis of both the start and total latency data indicated that the experimental animals ran significantly faster than the control Ss on Trials 4 to 7 of the conflict phase $(p<.05$ in all cases).

\section{DISCUSSION}

The most striking feature of this study is that rats with septal lesions were found to be impaired in a passive avoidance task under both massed and spaced conditions. This contrasts with the report of Liss (1968) who found that rats with portions of the hippocampus damaged were impaired in passive avoidance under spaced trial conditions, but did not differ from control Ss under massed trial conditions.

It would appear that, in addition to pre- and postoperative approach training, the ITI is a further parametric variable which affects septal- and hippocampal-lesioned animals differentially. The results of the present experiment suggest the possibility that a short-term memory dysfunction may be involved following hippocampal damage, but not as a consequence of septal injury.

However, the differential effects of the ITI following damage to the two limbic structures may have to be qualified. In the present experiment, the septal lesions damaged an extensive portion of the septum including areas having both afferent and efferent connections to anterior and posterior regions of the hippocampus (Raisman, 1966). The lesions reported by Liss (1968) were restricted to the posterior portion of the hippocampus. It may be that extensive hippocampal damage would 
result in passive avoidance behavior which would be as unaffected by the ITI as that found in the present work following extensive septal damage. Indirect support for this qualification is derived from the work of Coscina \& Lash (1969). These workers report that, with an ITI of 2-3 min, combined dorsal and ventral hippocampal damage by aspiration did result in passive avoidance deficits, whereas electrolytic lesions restricted to the posterior portion did not.

The similarity of all animals with respect to the percentage of total time that was spent in the startbox area is in accord with an earlier report (Fried, 1970) that the location of the approach-avoidance conflict does not differ between septal-damaged and control animals. In the previous report, a shock level of $0.2 \mathrm{~mA}$ was used and the conflict appeared to be at its maximum in the goalbox area, whereas, in the present study, in which a shock level of twice the intensity was u s e d, t h e $m$ a $x$ i m u m approach-avoidance conflict occurred in the startbox area.

\section{REFERENCES}

COSCINA, D. V., \& LASH, L. The effects of differential hippocampal lesions on a shock versus shock conflict. Physiology \& Behavior, 1969, 4, 227-233.

FRIED, P. A. Pre- and post-operative approach training and conflict resolution by septal and hippocampal lesioned rats. Physiology \& Behavior, 1970, 5, 975-979.

FRIED, P. A. Limbic system lesions in rats: Differential effects in an a pproach-avoidance task. Journal of Comparative \& Physiological Psychology, $1971,74,349-353$.

FRIED, P. A. The septum and behavior: A review. Psychological Bulletin, in press.

FRIED, P. A., \& GODDARD, G. V. The effects of hippocampal lesions at different stages of conflict in the rat. Physiology \& Behavior, 1967, 2, 325-330.
LISS, P. Avoidance and freezing behavior following damage to the hippocampus or fornix. Journal of Comparative \& Physiological Psychology, 1968, 66, 193-197.

MCCLEARY, R. A. Response-modulating functions of the limbic system: Initiation and suppression. In E. Stellar and J. M. Sprague (Eds.), Progress in physiological psychology. Vol. 1. New York: Academic Press, 1966. Pp. 209-272.

MIDDAUGH, L. D., \& LUBAR, J. F Interaction of septal lesions and experience on the suppression of punished responses. Physiology \& Behavior, 1970, 5, 233-237.

RAISMAN, $G$. The connexions of the septum. Brain, 1966, 89, 317-349.

THOMAS, G. J., HOSTETTER, G, \& BARKER, D. J. Behavior functions of the limbic system. In E. Stellar and J. M. Sprague (Eds.), Progress in physiological psychology. Vol. 2. New York: Academic Press, 1968. Pp. 230-311.

WISHART, T. B., \& MOGENSON, G. J Effects of lesions of the hippocampus and septum before and after passive avoidance training. Physiology \& Behavior, 1970, 5, 31-34. 